\title{
ANNOTATION
}

\section{The Eye and Spectacles in Heraldry}

Both spectacles and the eye are very rare charges in English heraldry. The Worshipful Company of Spectaclemakers of London (incorporated 1629), bears, "- argent, 3 pairs of spectacles vert, garnished or." This bearing smacks of the Vicar of Wakefield; Moses, with his gross of green spectacles, with copper rims and shagreen cases; a dead bargain.

Papworth and Morant, in their Ordinary of British Armorials (1874), give only two families who bear similar charges.

Wate. (Workman's MS.). "Argent, an oak tree growing out of a mount in base, vert ; on one of the branches, a pair of spectacles, azure ; on the top of the tree, an eye proper."

Watt. (Edinburgh). "Argent, in chief an human eye proper; in base an oak tree growing out of a mount, vert; all within a bordure gules."

There is a good deal of similarity about these two coats, and not much difference between the names of the families. Complicated coats such as these are pretty sure to be of late date.

Finally, the eye appears in the fine Chippendale book-plate of Hermann Heineken, M.D., who was physician to the Middlesex Hospital in 1749-1750. This plate shows a shield divided per pale, the husband's arms being on the dexter side and the wife's on the sinister. The eye occurs in the centre of the palm of a hand, couped at the wrist, on the sinister side of the shield. Oddly enough, the crest is an exactly similar hand, bearing an eye in the centre of the palm, between a pair of wings, addorsed. This strikes us as being excessively bad heraldry; females, with the exception of the Sovereign, not being allowed to bear crests by the laws of heraldry.

\section{ABSTRACTS}

\section{I.-MISCELLANEOUS}

(I) Smith, Kenneth, R.-An apparatus for exercising heterophoria and squint cases. Proc. Roy. Soc. of Med., p. 701, 1928.

(1) The construction of Smith's apparatus (the binoscope) for training binocular vision is based upon the characteristic fact observed in children's squint, namely, that the child sees with one eye only at one and the same time, and that when the eye which 